\title{
Seasonal Rainfall Prediction for Tamil Nadu Using Climate Predictability Tool
}

\section{G. Senbagavalli, N.K. Sathyamoorthy, S. Kokilavani, G.A. Dheebakaran and Patil Santosh Ganapati ${ }^{1}$}

Agro Climate Research Centre, ${ }^{1}$ Department of Physical Science and Information Technology, Tamil Nadu Agricultural University, Coimbatore-641 003, India E-mail: senbagavallibsc@gmail.com

\begin{abstract}
Seasonal rainfall prediction is potentially valuable input for agriculture and allied sectors. Climate Predictability Tool (CPT) is a computational statistical software and intended to facilitate the widespread development and dissemination of quality-controlled seasonal climate forecasts. In the present study, CPT was used to predict South West Monsoon (SWM) rainfall by utilizing the Canonical Correlation Analysis (CCA) technique. Results indicate that observed sea surface temperature (SST) from the ERSSTv5 model of March-April-May (MAM) months for the Nino 3.4 region exhibited a strong association with rainfall (the CCA score of 0.71 ). Thus, MAM SST was used to predict the SWM (2021) rainfall for 32 districts of Tamil Nadu. The prediction accuracy was tested with ROC score, Pearson correlation and 2AFC score. The good predictive skill of cross-validated hindcast in the below and the above-normal category of rainfall (1981-2020) was observed in 17 districts and poor discrimination was observed in 15 districts of Tamil Nadu.
\end{abstract}

